\title{
Echocardiography Effectiveness in Improving Diagnosis of Rheumatic Heart Disease in North Darfur: A Hospital-based Study
}

\author{
Mohammed Elmujtba Adam Essa Adam ${ }^{1,2 *}$, Sherihan Mohammed Elkundi Osman ${ }^{3}$, \\ Daralsalam Ishag Ateem Abdalrasoul ${ }^{1}$, Ibrahim Adam Osman Yagoup ${ }^{1,2}$, \\ Mustafa Mohamed Ali Hussein ${ }^{1,2}$, Mutwaly Defealla Yousif Haron ${ }^{1,2}$, \\ Ziryab Imad Taha Mahmoud ${ }^{4,2}$ and Abdelkareem A. Ahmed ${ }^{2,5^{*}}$
}

\begin{abstract}
${ }^{1}$ Department of Medicine, Faculty of Medicine, Al-Fashir University, Al-Fashir, Sudan; ${ }^{2}$ Department of Clinical Medicine, Medical and Cancer Research Institute (MCRI), Nyala, Sudan; ${ }^{3}$ Department of Molecular Medicine, Institute of Endemic Diseases, University of Khartoum, Khartoum, Sudan; ${ }^{4}$ Department of Internal Medicine, Faculty of Medicine, University of Bahri, Khartoum, Sudan; ${ }^{5}$ Department of Physiology and Biochemistry, Faculty of Veterinary Science, University of Nyala, Nyala, Sudan
\end{abstract}

\begin{abstract}
Background: Acute rheumatic fever (ARF) is an inflammatory disease caused by autoimmune responses to bacterial infection. Rheumatic heart disease (RHD) damages one or more heart valves through recurrent episodes of ARF. We aimed to determine the changes in sensitivity, specificity and predictive values in RHD Jones diagnostic guidelines following the inclusion of echocardiograph as an additional diagnostic tool for RHD.
\end{abstract}

Methods: This is a retrospective cross-sectional study done in the echocardiography center of Al-Fashir teaching hospital. We included a total of 1,103 patients who presented at our hospital and had a diagnosis of RHD, ischemic heart disease or congestive heart disease during 2011-2017.

Results: Among the RHD patients, screening with echocardiography was associated with increases of the sensitivity value, positive predictive value and specificity value by $18.1 \%, 8.1 \%$ and $1 \%$, as compared to their initial diagnoses by Jones criteria alone, which were primarily based on clinical presentations. Mitral stenosis was the most common RHD abnormality, followed by aortic and tricuspid valve regurgitation. North Darfur state was found to have the lowest prevalence of RHD in all geographical parts of Sudan that have been studied. The female to male ratio was 3:1.

Conclusions: Our data highlight the important role of echocardiography in diagnosing RHD complications through improved diagnostic sensitivity, positive predictive value and specificity.

Keywords: Early diagnosis; Echocardiography; Mitral stenosis; North Darfur state; Rheumatic heart disease.

Abbreviations: ARF, acute rheumatic fever; RHD, rheumatic heart disease; RF, rheumatic fever.

Received: August 27, 2019; Revised: October 16, 2019; Accepted: November 07, 2019

*Correspondence to: Abdelkareem Abdallah Ahmed, Department of Physiology and Biochemistry, Faculty of Veterinary Science, University of Nyala, Nyala, PO Box: 155 Nyala, Sudan. Fax: +249711833123; E-mail: kareemo151@gmail.com; Mohammed Elmujtba Adam Essa Adam, Faculty of Medicine, Al-Fashir University, Al-Fashir, Sudan. Tel: +249907009378; E-mail: Awadali818@yahoo.com

How to cite this article: Adam MEAE, Osman SME, Abdalrasoul DIA, Yagoup IAO Hussein MMA, Haron MDY, Mahmoud ZIT, Ahmed AA. Echocardiography Effectiveness in Improving Diagnosis of Rheumatic Heart Disease in North Darfur: A Hospital-based Study. Exploratory Research and Hypothesis in Medicine 2020;5(1):11-18. doi: 10.14218/ERHM.2019.00020.
Introduction

Acute rheumatic fever (ARF) is a type of disease caused by bacterial infection, commonly involving groups with a $\beta$ hemolytic Streptococci and leading to an autoimmune inflammatory response. Most of the body's organs, such as the heart, brain, joints and skin, can also be affected by the disease. The recurrent episodic valve damage to the heart in ARF are known as rheumatic heart disease (RHD). ${ }^{1,2}$ Both diseases are common in low socioeconomic communities. ${ }^{3}$ More than $0.5 \%$ of school-age children are suffering from RHD across the globe, and the incidence is increased in the sub-Saharan region of Africa by nearly half a million patients annually. ${ }^{4-6}$ This disease causes damage to the heart valves and the most common consequent abnormality is mitral regurgitation. ${ }^{7,8}$ There is a growing concern for patients with severe conditions 
without access to cardiac surgery, which could lead to a potential risk of death being imminent. Reportedly, $20 \%$ of patients die before the age of 5 years and $80 \%$ before the age of 25 years. ${ }^{9}$

In regard to the pathology and pathogenesis of RHD, the calcification in the mitral valve is not merely an inactive "dystrophic" process but it is a regulated inflammatory process with osteoblast and neo-angiogenesis markers' expression. ${ }^{10}$ The World Health Organization (commonly referred of as WHO) Consultant's Report stated that any patient diagnosed by echocardiography with a silent rheumatic valve should be considered and treated as RHD until other proof is available. ${ }^{11}$ Accurate diagnosis is important to avoid long-term treatment for those who have been diagnosed and also to prevent further heart damage and the need for surgical intervention (for those who are underdiagnosed). Currently, there is no diagnostic test for RHD, and the diagnosis is based solely on the clinical recognition of the major and minor criteria of Jones (guidelines published in 1944 by Dr T. Duckett Jones, modified in 2015) with evidence of Streptococcal throat infection. $^{12}$

The estimated risk for developing rheumatic fever (RF) after a streptococcal pharyngitis episode is $0.3-3 \%,{ }^{13}$ and a small percentage of RF develops as RHD. The primary risk factor is Streptococcal throat infection. Other types of infections, such as of group A Streptococci, may lead to RF, as in pyoderma (skin infection); however, age, sex, urban residence, overcrowding, poverty, offspring of working mothers, and mother illiteracy are also potential risk factors. ${ }^{14}$ The objective of this study was to determine the incidence, prevalence and risk factors of RHD among children and adults in North Darfur State, and to estimate the specificities, sensitivities, and positive predictive values of adding echocardiograph to the routine of diagnosing RHD patients.

\section{Methods}

\section{Study area}

North Darfur State is one of the five States composing the Darfurian region, with an area of $296,420 \mathrm{Km}^{2}$ and a total population of 2,296,068 in 2017 (Central Statistical Agency of Sudan, 2017 report). Al-Fashir, its capital, had 264.734 residents in 2006; however, that number decreased nearly to half in the last 5 years due to conflict in the area.

\section{Study design}

This is a retrospective study; the data was collected from Al-Fashir Teaching Hospital. Scientific and ethical approvals were granted by the Scientific and Ethics Committees of the Institute of Endemic Diseases, University of Khartoum. Addition approvals were obtained from the North Darfur State Ministry of Health and AlFashir Teaching Hospital Management Board. The data covered the period from January 2011 to December 2017. The data collected from the hospital files included the clinical records of patients with confirmed RHD, RF and other cardiac diseases. Demographic and clinical data were extracted along with each patient's age, sex, address, clinical presentations, valve involvement, and final diagnosis. All the studied patients had been selected to be confirmed by echocardiography after eliciting clinical suspicion.

The steps of the disease diagnosis begun from the outpatient yard, where the disease history and clinical examinations were performed for all patients. After diagnostic suspicion, all of the patients were confirmed by echocardiography (SusKo, CH5-2Transducer; Siemens), which established the diagnosis. The severity was determined by the American Society of Echocardiography (commonly known as ASE) modified criteria, and the valve lesion was defined according to the jet width and camper to the jet ratio $(5 \mathrm{~mm}$ and more to the left atrium ratio of $20 \%$ was considered severe mitral regurgitation; and if the jet-valve ratio with the jet width increased severity of the valve became more intense, a $3 \mathrm{~mm}$ jet width with $25 \%$ left ventricular outflow tract as confirmed by aortic regurgitation echocardiography). The Doppler mean gradient and valve appearance were both used to calculate the mitral stenosis. The clinical examinations included several processes, and careful cardiac examination was performed in supine and left lateral decubitus position by an experienced physician. Patients with organic murmur were detected clinically and confirmed by echocardiography, then classified as patients with clinically-detected RHD.

\section{Statistical analysis}

The statistical software package SPSS (version 17.0) was used to analyze all the collected data of RHD as percentages, categories and $p$-values for statistical significance testing. Evaluation data were analyzed by one-way analysis of variance (referred to as ANOVA). The level of statistical significance was set as $p<0.05$.

\section{Results}

The study included in total 1,103 patients who were confirmed by echocardiography from January 2011 to December 2017. All patients who were screened by echocardiography were confirmed with the following diagnoses: RHD, ischemic heart disease, congestive heart disease and cardiomyopathy, $(35 \%, 29.2 \%, 20 \%$ and $15.8 \%$ respectively) (Fig. 1). We found that the most affected age groups among all the patients were those above 25 years, and that both the age groups between $15-25$ years and under 15 years have an equal incidence of RHD (38\%, 31\%,31\% respectively) (Fig. 2). The incidence of RHD was found to be higher in females than males, with a ratio of 3:1 (Fig. 3) (Table 1).

Most of the patients in the year 2011 had three-valve involvements, double valve involvements and an isolated valve $(55.9 \%$, $26.41 \%$ and $14.71 \%$ respectively). This contrasted the following years, which showed a semi-steady decrease of the three-valve involvements in the RHD patients and that those patients with three-valve lesions became the fewest among the collective patients with different valves lesions, followed by the isolated valve involvement patients and dominated by the double valve involvement patients $(4 \%, 38.8 \%$ and $57.2 \%$ respectively in 2015$)$. In total, double valve involvement had the greatest incidence, followed by an isolated valve then the three-valve involvement (40.9\%, 35.6\% and $23.5 \%$ respectively) (Table 2 ). The peak incidence of the three-valve involvement was the year $2011(55.9 \%)$, and the lowest incidence year was 2015 (4.1\%) (Fig. 4). The most affected valve in our RHD patients was found to be the mitral valve, followed by the aortic then the tricuspid valve $(56.9 \%$, $27.2 \%$ and $15.9 \%$ respectively) (Table 3 ). The highest incidences of the mitral valve were in 2014 and 2017 , in which $100 \%$ of patients had mitral valve lesion with or without other affected valves (Table 4).

When comparing the same patients, who were diagnosed by Jones criteria before and after the screened echocardiography to confirm the diagnosis, we found that the echocardiography screen- 


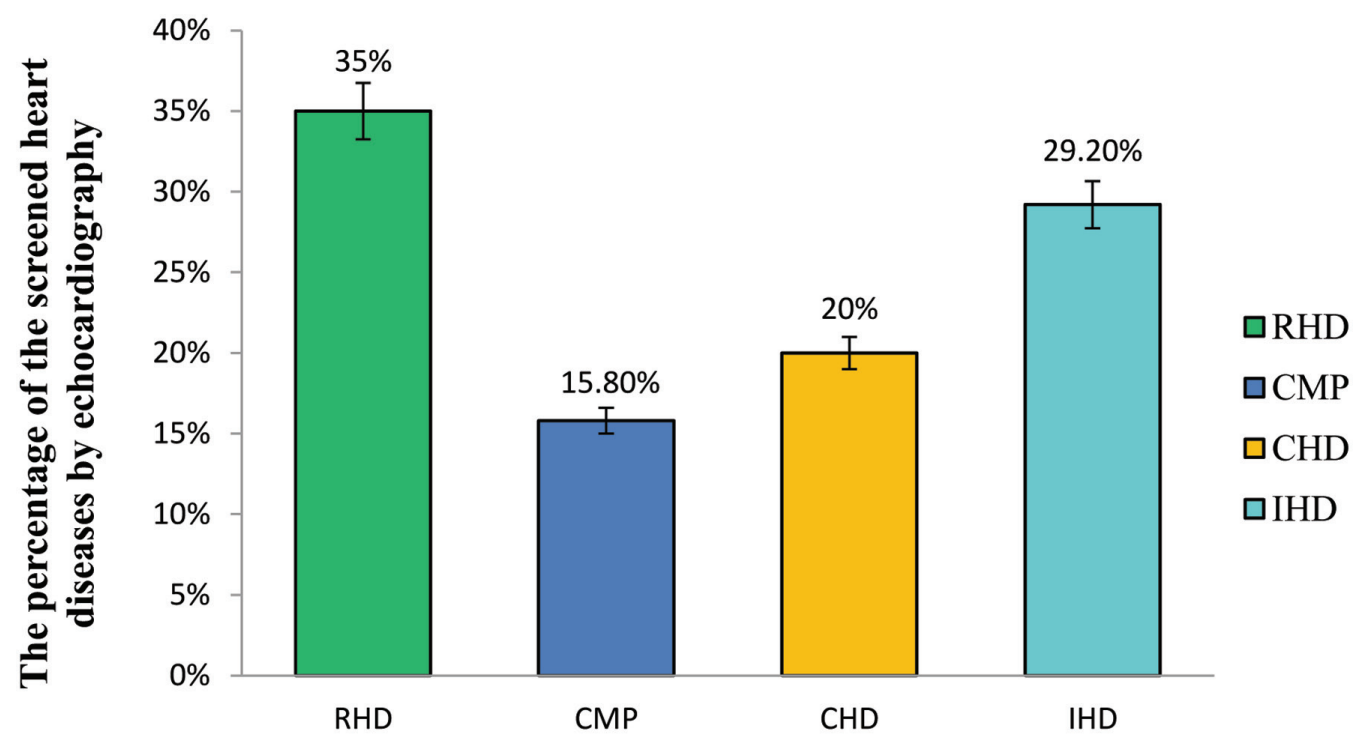

Types of heart diseases screened by echocardiography

Fig. 1. Jones criteria for diagnosing rheumatic fever. Data are hospital diagnoses from the period of 2011-2017.

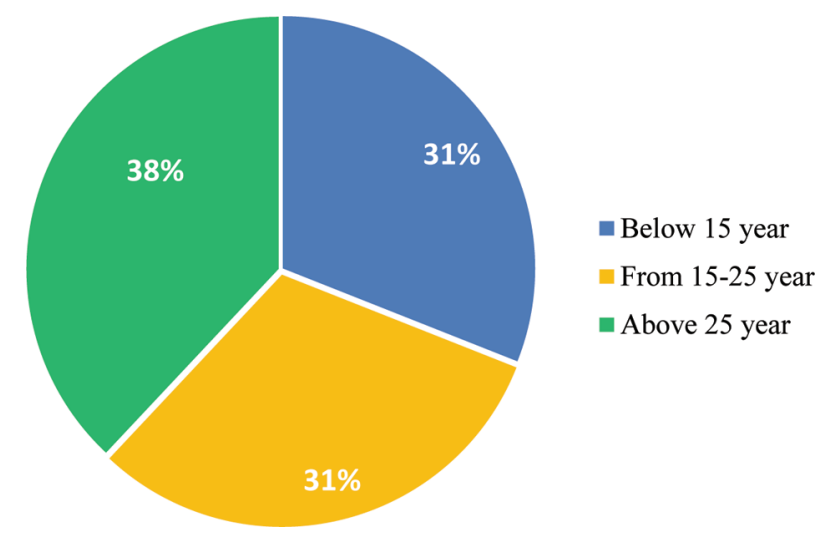

Fig. 2. Age groups of rheumatic heart disease in North Darfur State patients.

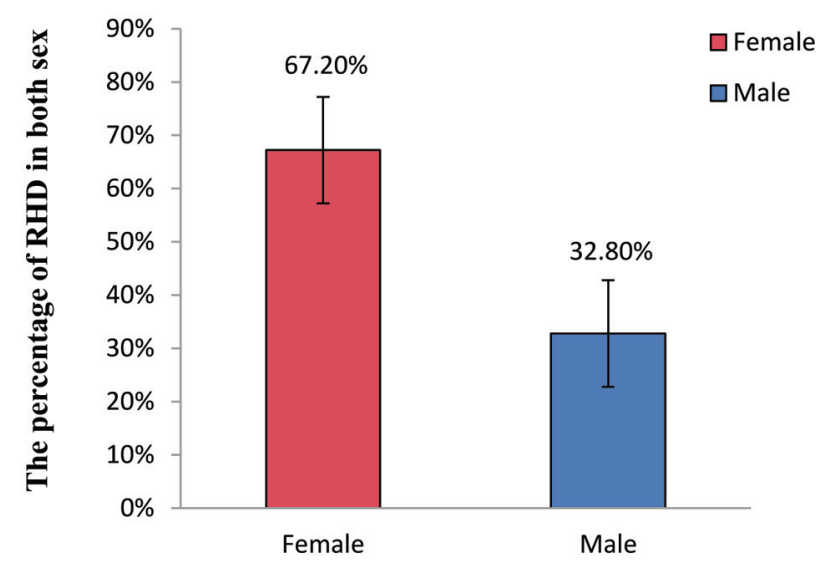

Fig. 3. Incidence rate between male/female patients with rheumatic heart disease. ing adds better sensitivity, positive predictive value and specificities $(18.1 \%, 8.1 \%$ and $1 \%)$ (Table 5). The peak incidence year with RHD patients was 2011 (17.6\%) and the least affected year was 2017 (11.6\%). The years 2012, 2013, 2014, 2015 and 2016 had a fluctuating range of incidence $(14.7 \%, 16.3 \%, 13.3 \%, 12.7 \%$ and $13.9 \%$ ) (Table 6, Fig. 5). We also found that mitral stenosis is more common than mitral regurgitation, by a $12.4 \%$ difference. The mitral stenosis represents $56.2 \%$ of all the mitral involvement patients, in comparison to $43.8 \%$ represented by the mitral regur-

Table 1. Male, female differences with rheumatic heart disease

\begin{tabular}{lllll}
\hline & Frequency & $\%$ & Valid \% & $p$-value \\
\hline Valid & & & & \\
Male & 127 & 32.8 & 32.8 & $<0.05$ \\
Female & 260 & 67.2 & 67.2 & $<0.05$ \\
Total & 387 & 100 & 100 & \\
\hline
\end{tabular}

Table 2. Number and percentage of valve involvement in rheumatic heart disease patients from 2011-2017

\begin{tabular}{llll}
\hline Year & Isolated valve & Double valve & Three valves \\
\hline 2011 & $14.71 \%$ & $26.41 \%$ & $55.88 \%$ \\
2012 & $35.10 \%$ & $28 \%$ & $36.90 \%$ \\
2013 & $44.40 \%$ & $44.40 \%$ & $11.20 \%$ \\
2014 & $53 \%$ & $39.20 \%$ & $7.80 \%$ \\
2015 & $38.80 \%$ & $57.20 \%$ & $4 \%$ \\
2016 & $37.10 \%$ & $50 \%$ & $12.90 \%$ \\
2017 & $31.20 \%$ & $42.20 \%$ & $26.60 \%$ \\
Total & $35.60 \%$ & $40.90 \%$ & $23.50 \%$ \\
\hline
\end{tabular}




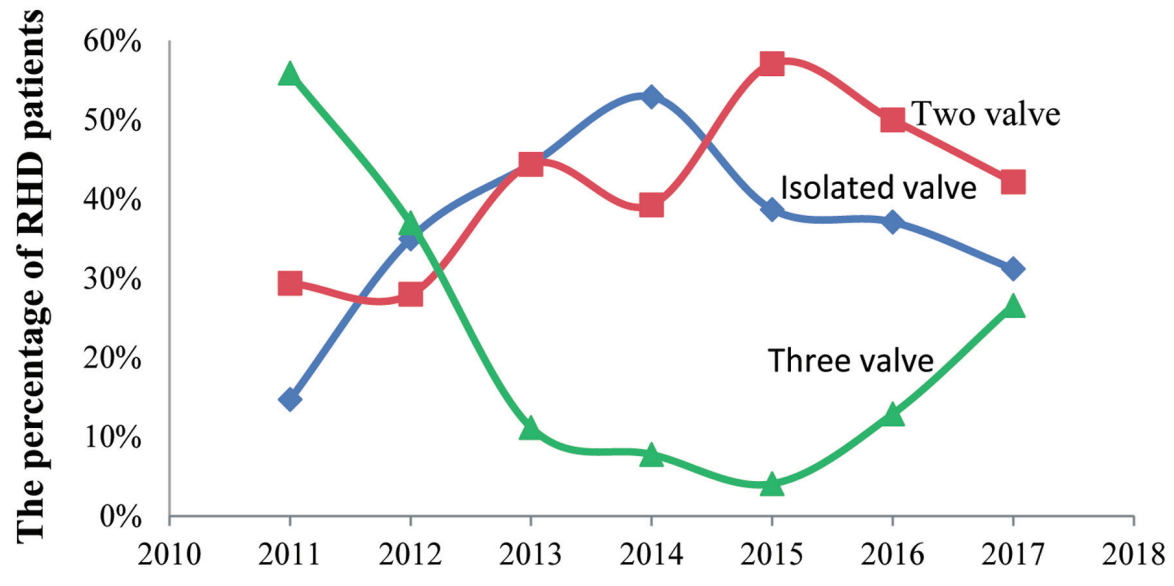

The incidence of valves involvment with time

Fig. 4. Prevalence of valvular abnormality in patients with rheumatic heart disease.

gitation.

The most common aortic type of lesion has been aortic regurgitation, found in $84.7 \%$ of the patients with aortic valve involvement, and the least common type of aortic involvement has been aortic stenosis. We also found all the patients with tricuspid lesion had tricuspid regurgitation with zero tricuspid stenosis. The most common clinical presentation of RHD patients has been arthritis, followed by carditis, arthralgia, chorea and erythema marginatum $(62 \%, 41.1 \%, 33.5 \%, 11.4 \%$ and $1 \%)$. Most of the patients were diagnosed with more than one feature (Fig. 6).

Table 3. Accumulative percentages and frequencies of the three-valve involvements in all the rheumatic heart disease patients

\begin{tabular}{cllll}
\hline \multicolumn{1}{l}{ Frequency } & Percent & Valid Percent & $\boldsymbol{p}$-value \\
\hline Valid & & & & \\
Mitral & 377 & 56.9 & 56.9 & $<0.05$ \\
Aortic & 180 & 27.2 & 27.2 & $<0.05$ \\
Tricuspid & 105 & 15.9 & 15.9 & $<0.05$ \\
Total & 662 & 100 & 100 & \\
\hline
\end{tabular}

Table 4. Percentages of cardiac valve lesions' involvement in rheumatic heart disease patients from 2011-2017

\begin{tabular}{llll}
\hline Year & Mitral & Aortic & Tricuspid \\
\hline 2011 & $91.1 \%$ & $51.4 \%$ & $39.7 \%$ \\
2012 & $98.2 \%$ & $47.3 \%$ & $14 \%$ \\
2013 & $98.4 \%$ & $44.4 \%$ & $23.8 \%$ \\
2014 & $100 \%$ & $37.2 \%$ & $17.6 \%$ \\
2015 & $98 \%$ & $53 \%$ & $14.2 \%$ \\
2016 & $98.1 \%$ & $40.7 \%$ & $37 \%$ \\
2017 & $100 \%$ & $51.1 \%$ & $42.22 \%$ \\
\hline
\end{tabular}

The table demonstrates the percentage of each valve involvement annually. As the patients can have all three valves lesions at the same time, the percentage are overlapping.

\section{Discussion}

RF was first detected by Wig in 1935 and since then most of the studies conducted in ARF and RHD patients have been identified by many risk factors associated with the disease, ${ }^{12}$ such as poverty and low health access. ${ }^{13-20}$

Most global studies show an inconsistent association of the male to female ratio. The epidemiological data indicate there is the same prevalence of RHD in both sexes, ${ }^{21}$ which is in contrast to our study, which demonstrated a higher incidence in females than males (being

Table 5. Sensitivity, specificity and positive predictive value changes before and after addition of echocardiograph to rheumatic heart disease diagnosis

\begin{tabular}{lll}
\hline & $\begin{array}{l}\text { Jones criteria } \\
\text { alone }\end{array}$ & $\begin{array}{l}\text { Jones criteria with } \\
\text { echocardiography }\end{array}$ \\
\hline Sensitivity & $51.2 \%$ & $69.3 \%$ \\
Specificity & $97 \%$ & $98 \%$ \\
Positive predictive value & $88.3 \%$ & $96.4 \%$ \\
$p$-value & $<0.05$ & $<0.05$ \\
\hline
\end{tabular}

Table 6. Percentage of rheumatic heart disease from 2011-2017

\begin{tabular}{llllll}
\hline \multicolumn{1}{c}{ Year } & Frequency & Percent & Valid percent & $\boldsymbol{p}$-value \\
\hline Valid & & & & & \\
& 2011 & 68 & 17.6 & 17.6 & $<0.05$ \\
2012 & 57 & 14.7 & 14.7 & $<0.05$ \\
2013 & 63 & 16.3 & 16.3 & $<0.05$ \\
2014 & 51 & 13.2 & 13.2 & $<0.05$ \\
2015 & 49 & 12.7 & 12.7 & $<0.05$ \\
2016 & 54 & 14 & 14 & $<0.05$ \\
2017 & 45 & 11.6 & 11.6 & $<0.05$ \\
Total & 387 & 100 & 100 & \\
\hline
\end{tabular}




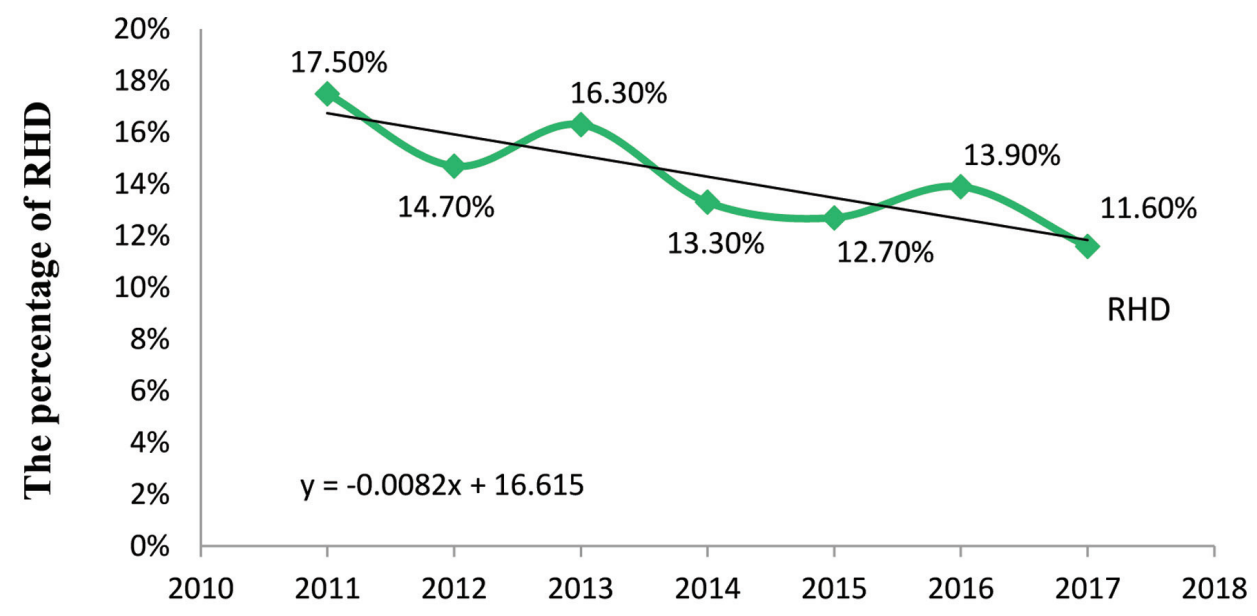

The incidence of RHD in Al Fashir teaching hospital

Fig. 5. Prevalence of rheumatic heart disease in Al-Fashir Teaching Hospital from 2011-2017.

3:1). Our findings are in line with previous studies conducted in Sudan and some parts of Asia, such as India and Pakistan, which gave similar results but showed a lower female to male ratio. ${ }^{21-23}$ This could be explained by women seeking medical care more than men, especially during the antenatal care period, or the opposite, where women are less likely to seek medical care when they have a strep throat infection; however, no clear explanation has been identified. In addition, there is an elevated infection risk of group A streptococcal infection, and RHD may develop if not treated properly; this constitutes $60 \%$ of heart disease during pregnancies. ${ }^{24,25}$

Our study found a higher rate of sensitivity and specificity in using the echocardiography to diagnose RHD compared by traditional means of screening, such as auscultation. There have been several studies in the literature that produced the same finding. ${ }^{26,27}$ Other studies have also detected the sensitivity rate of $73 \%$ and the positive predictive value of $92 \%$ in using echocardiography aligning with the reference criteria. ${ }^{28}$
The incidence of RHD in North Darfur was found in our study to be less than in any other area in Sudan which had been studied, such as South Darfur, which showed 3.3\% in Nyala camps during the year 2016. Khartoum, being the capital city of North Darfur, was estimated to have $0.03 \%$, and that prevalence are dominated by the North Kordofan state (with $6.1 \%$ of RHD). ${ }^{23-25}$ On the other hand, our study revealed that North Darfur has only $0.03 \%$ of RHD, which reduced to $0.019 \%$ in 2017 (the population density of North Darfur was obtained from the Central Statistical Organization report).

Another study showed the age groups from 11-30 years to be the most affected with RHD. ${ }^{23}$ Similarly, our study confirmed that age groups above 25 years have higher incidence. This may be related to the lack of health services, timely diagnosis and treatment. There are general agreements on mitral valve, which has been the valve disease most associated with RHD, and the mitral regurgitation, as the most common type of lesion in the valve. ${ }^{24,29}$ Our

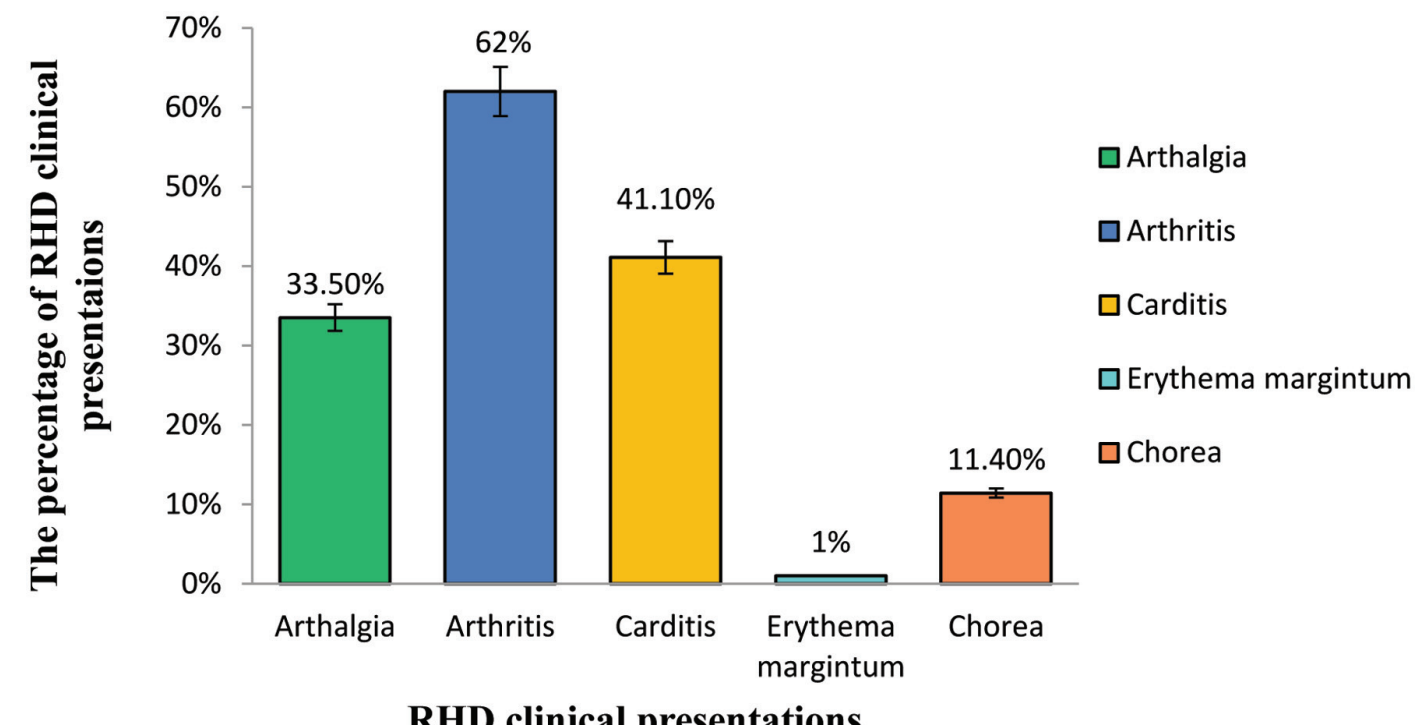

Fig. 6. Clinical presentation of the rheumatic heart disease patients. 


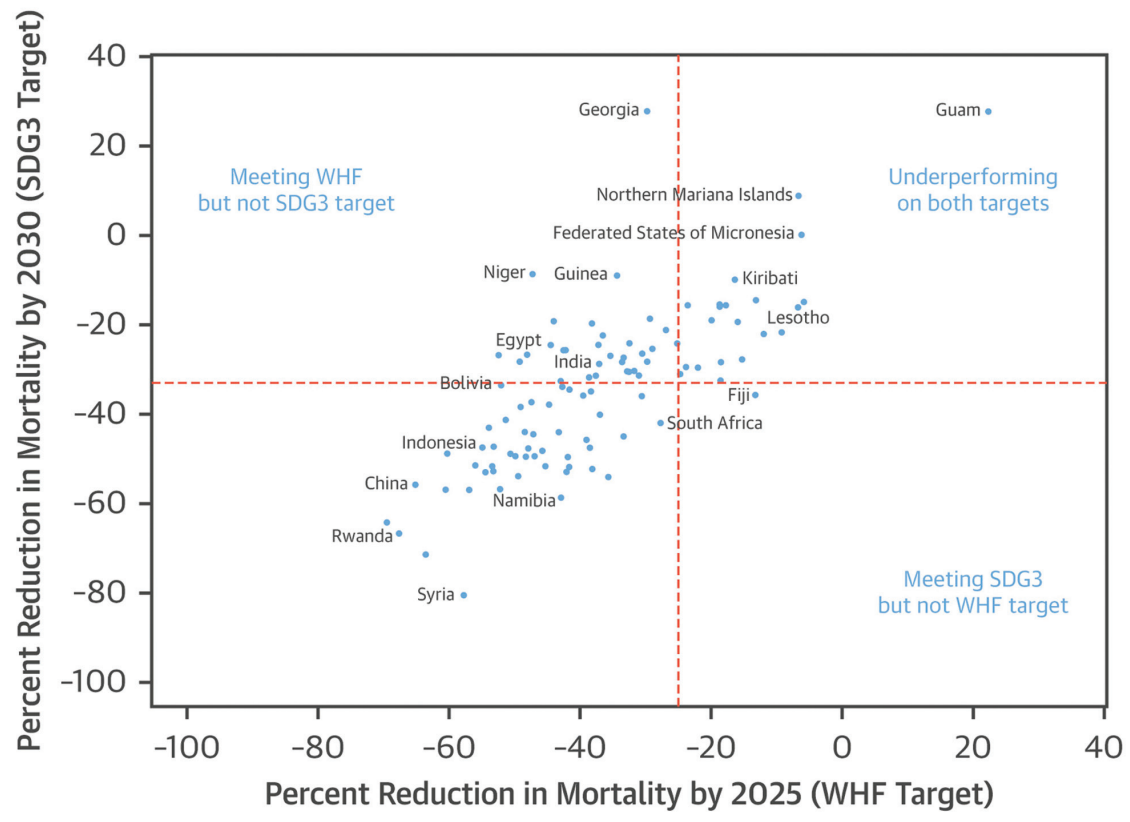

Fig. 7. Projected decrease in age-specific mortality from rheumatic heart disease based on country trends from 2000 to 2015 . The $x$-axis demonstrates the total percentage reduction in mortality for those aged below 25 years (WHF) target between 2013 and the year 2025 , if 2000 to 2015 trends continue. The y-axis illustrates all percent reduction in mortality for those aged 30-69 years (Sustainable Development Goal 3 [SDG3] target) between 2015 and 2030, if 2000 to 2015 trends continue.

analyses also revealed the mitral valve to be the highest involved but also found mitral stenosis to be more common when compared to mitral regurgitation. The inconsistency of those findings may indicate the higher prevalence of elderly patients, as mitral stenosis occurs in advanced ARF. ${ }^{30}$

To control both RHD and RF, there are many factors that should be considered, starting with benzathine penicillin G administration, ${ }^{31}$ vaccine availability, primordial, overcrowding, and improving primary and secondary prevention against the disease, according to the WHO. ${ }^{31,32}$ The secondary prevention to RF is the continuous provision of some type of antibiotic to patients with an exposed history of ARF and documented RHD, ${ }^{31}$ with consideration to treatment availability and no surgical access. In valvular disease patients this is particularly important. ${ }^{33,34}$ The last expansion of the echocardiography screening programs led to a reduction in the burden of RHD and it will continue to better identify patients while they are asymptomatic, like in silent RHD. The continuous data provided will help in estimating the prevalence of the diseases and their complications with annual bases.

The study presented herein carries some limitations, such as having no updated population census in Sudan, no available data in regard to patient follow-up, and so on.

Future research directions, prospectives, predictions and hypothesis

In 2013, the World Heart Federation called for a $25 \%$ reduction in RHD mortality amid individuals aged $<25$ years before the year 2025. ${ }^{35}$ Recently, the United Nations Sustainable Development Goal 3 (referred to as SDG3) prospected a 1/3 reduction in premature death due to non-communicable disease by the year $2030 .{ }^{36}$ Predicting that trends in mortality over the last 15 years hold, many endemic regions are in line to achieve either one of or both targets
(Fig. 7). ${ }^{37}$

There are some hypotheses about the role of RHD in being a risk factor for some neurological diseases, such as with stroke, as it has been detected that patients with mitral stenosis and atrial fibrillation have increased $4 \%$ liability to have stroke. ${ }^{38}$ Yet, only a few studies are being done in this matter, but future studies will likely clarify the exact role.

\section{Conclusions}

This was a retrospective hospital-based study which concluded that females were more vulnerable to RHD. Moreover, over 25 years-old is the most affected age group, and the incidence of valve involvement in RHD decreases with time. The sensitivity, specificity and positive predictive value have improved after the addition of echocardiography to the Jones criteria.

\section{Acknowledgments}

The authors are very grateful to the Al-Fashir Hospital administration staff for their support in conducting this research.

\section{Ethics approval and consent to participate}

Obtained.

Consent for publication

Not applicable. 
Funding

No funds have been received in relation to this study or its publication.

\section{Conflict of interest}

All authors declare that they have no conflicts of interest.

\section{Author contributions}

Performing the cardiovascular examination, echocardiography screening and confirming the diagnosis (DIAA), scientific writing and data analysis (MEAEA, SMEO, ZITM, MDYH), collecting the data from the hospital records (IAOY, MMAH), supervising the study (AAA).

\section{References}

[1] Marijon E, Mirabel M, Celermajer DS, Jouven X. Rheumatic heart disease. Lancet 2012;379(9819):953-964. doi:10.1016/S01406736(11)61171-9.

[2] Kaplan MH, Bolande R, Rakita L, Blair J. Presence of Bound Immunoglobulins and Complement in the Myocardium in AcuteRheumatic Fever. Association with Cardiac Failure. N Engl J Med 1964;271:637645. doi:10.1056/NEJM196409242711301.

[3] Watkins DA, Zuhlke LJ, Engel ME, Mayosi BM. Rheumatic fever: neglected again. Science 2009;324(5923):37. doi:10.1126/ science.324.5923.37b.

[4] Gordis L. The virtual disappearance of rheumatic fever in the United States: lessons in the rise and fall of disease. T. Duckett Jones memorial lecture. Circulation 1985;72(6):1155-1162. doi:10.1161/01. cir.72.6.1155.

[5] Carapetis JR, McDonald M, Wilson NJ. Acute rheumatic fever. Lancet 2005;366(9480):155-168. doi:10.1016/S0140-6736(05)66874-2.

[6] Carapetis JR, Steer AC, Mulholland EK, Weber M. The global burden of group A streptococcal diseases. Lancet Infect Dis 2005;5(11):685694. doi:10.1016/S1473-3099(05)70267-X.

[7] Chockalingam A, Gnanavelu G, Elangovan S, Chockalingam V. Clinical spectrum of chronic rheumatic heart disease in India. J Heart Valve Dis 2003;12(5):577-581.

[8] Tissier R, Chetboul V, Moraillon R, Nicolle A, Carlos C, Enriquez B, et al. Increased mitral valve regurgitation and myocardial hypertrophy in two dogs with long-term pimobendan therapy. Cardiovasc Toxicol 2005;5(1):43-51. doi:10.1385/ct:5:1:043.

[9] Remenyi B, Carapetis J, Wyber R, Taubert K, Mayosi BM, World Heart F. Position statement of the World Heart Federation on the prevention and control of rheumatic heart disease. Nat Rev Cardiol 2013;10(5):284-292. doi:10.1038/nrcardio.2013.34.

[10] Viswanathan V. Acute rheumatic fever. Indian Journal of Rheumatology 2012;7(5):36-43. doi:10.1016/S0973-3698(12)60027-2.

[11] Guilherme L, Kalil J. Rheumatic fever: How streptococcal throat infection triggers an autoimmune disease. In: Shoenfeld Y, Rose NR. Infection and autoimmunity. Amsterdam, Elsevier. 2004:321-330.

[12] Gewitz MH, Baltimore RS, Tani LY, Sable CA, Shulman ST, Carapetis J, et al. Revision of the Jones criteria for the diagnosis of acute rheumatic fever in the era of Doppler echocardiography: a scientific statement from the American Heart Association. Circulation 2015;131(20):1806-1818. doi:10.1161/CIR.0000000000000205.

[13] Kumar RK, Tandon R. Rheumatic fever \& rheumatic heart disease: the last 50 years. Indian J Med Res 2013;137(4):643-658.

[14] Kasmaei P, Atrkar-Roushan Z, Majlesi F, Joukar F. Mothers' knowledge about acute rheumatic fever. Paediatr Nurs 2008;20(9):32-34. doi:10.7748/paed2008.11.20.9.32.c6825.
[15] Kumar R, Vohra H, Chakraborty A, Sharma YP, Bandhopadhya S, Dhanda $\mathrm{V}$, et al. Epidemiology of group A streptococcal pharyngitis \& impetigo: across-sectional \& follow up study in a rural community of northern India. Indian J Med Res 2009;130(6):765-771.

[16] Carapetis JR, Currie BJ, Kaplan EL. Epidemiology and prevention of group A streptococcal infections: acute respiratory tract infections, skin infections, and their sequelae at the close of the twentieth century. Clin Infect Dis 1999;28(2):205-210. doi:10.1086/515114.

[17] Nordet P, Lopez R, Duenas A, Sarmiento L. Prevention and control of rheumatic fever and rheumatic heart disease: the Cuban experience (1986-1996-2002). Cardiovasc J Afr 2008;19(3):135-140.

[18] Allen LB, Allen M, Lesa RF, Richardson GE, Eggett DL. Rheumatic fever in Samoa: education as prevention. Pac Health Dialog 2011;17(1):107-118.

[19] Orün UA, Ceylan O, Bilici M, Karademir S, Ocal B, Senocak F, et al. Acute rheumatic fever in the Central Anatolia Region of Turkey: a 30-year experience in a single center. Eur J Pediatr 2012;171(2):361368. doi:10.1007/s00431-011-1555-x.

[20] Carapetis JR. Rheumatic heart disease in developing countries. N Engl J Med 2007;357(5):439-441. doi:10.1056/NEJMp078039.

[21] Rizvi SF, Khan MA, Kundi A, Marsh DR, Samad A, Pasha O. Status of rheumatic heart disease in rural Pakistan. Heart 2004;90(4):394399. doi:10.1136/hrt.2003.025981.

[22] Agarwal AK, Yunus M, Ahmad J, Khan A. Rheumatic heart disease in India. J R Soc Health 1995;115(5):303-309. doi:10.1177/1466 42409511500509.

[23] Ali S, Domi SB, Elfaki AM, Talib KA, Abdelrahman MH, Adam MS, et $a l$. The echocardiographic prevalence of rheumatic heart disease in North Kordofan and initiation of a control program. Sudan Medical Journal 2017;53(2):63-68.

[24] Manjunath CN, Srinivas P, Ravindranath KS, Dhanalakshmi C. Incidence and patterns of valvular heart disease in a tertiary care highvolume cardiac center: a single center experience. Indian Heart J 2014;66(3):320-326. doi:10.1016/j.ihj.2014.03.010.

[25] Ahmed K, Elfil A, Hamid HM, Saeed A, Ali A. Epidemiology of cardiac disease during pregnancy in Khartoum Hospital, Sudan. J Women's Health Care 2015;4(2):227. doi:10.4172/2167-0420.1000227.

[26] Marijon E, Celermajer DS, Tafflet M, El-Haou S, Jani DN, Ferreira B, et al. Rheumatic heart disease screening by echocardiography: the inadequacy of World Health Organization criteria for optimizing the diagnosis of subclinical disease. Circulation 2009;120(8):663-668. doi:10.1161/CIRCULATIONAHA.109.849190.

[27] Marijon E, Ou P, Celermajer DS, Ferreira B, Mocumbi AO, Jani D, et al. Prevalence of rheumatic heart disease detected byechocardiographic screening. N Engl J Med 2007;357(5):470-476. doi:10.1056/ NEJMoa065085.

[28] Mirabel M, Celermajer DS, Ferreira B, Tafflet M, Perier MC, Karam N, et al. Screening for rheumatic heart disease: evaluation of a simplified echocardiography-based approach. Eur Heart J Cardiovasc Imaging 2012;13(12):1024-1029. doi:10.1093/ehjci/jes077.

[29] Olson LJ, Subramanian R, Ackermann DM, Orszulak TA, Edwards WD. Surgical pathology of the mitral valve: a study of 712cases spanning 21 years. Mayo Clin Proc 1987;62(1):22-34. doi:10.1016/s00256196(12)61522-5.

[30] Hall P, Biorck G. The natural history of rheumatic valvular heart disease and its bearing upon the results of surgery for mitral stenosis. Acta Rheumatol Scand 1958;4(2):70-78. doi:10.3109/ rhe1.1958.4.issue-1-4.09.

[31] Moser M, Leo O. Key concepts in immunology. Vaccine 2010;28(Suppl 3):C2-C13. doi:10.1016/j.vaccine.2010.07.022.

[32] Guilherme L, Kohler KF, Postol E, Kalil J. Genes, autoimmunity and pathogenesis of rheumatic heart disease. Ann Pediatr Cardiol 2011;4(1):13-21. doi:10.4103/0974-2069.79617.

[33] Cilliers AM. Rheumatic fever and its management. BMJ 2006;333(7579):1153-1156. doi:10.1136/bmj.39031.420637.BE.

[34] Essa MEA, Ahmed AA, Osman SME. PREVALENCE OF PNEUMONIA IN SOUTH DARFUR STATE-SUDAN DATA COMPARED FROM 2009 THROUGH 2013. Eur J Biomed Pharm Sci 2017;4(3):32-35.

[35] Remenyi B, Carapetis J, Wyber R, Taubert K, Mayosi BM, World Heart F. Position statement of the World Heart Federation on the prevention and control of rheumatic heart disease. Nat Rev Cardiol 
2013;10(5):284-292. doi:10.1038/nrcardio.2013.34.

[36] United Nations. Sustainable Development Goals: 17 Goals to Transform Our World. Goal 3: Ensure Healthy Lives and Promote WellBeing For All at All Ages. New York, United Nations. 2016.

[37] Watkins DA, Beaton AZ, Carapetis JR, Karthikeyan G, Mayosi BM, Wyber $\mathrm{R}$, et al. Rheumatic heart disease worldwide: JACC scientific expert panel. J Am Coll Cardiol 2018;72(12):1397-1416. doi:10.1016/j.jacc.2018.06.063.

[38] Oldgren J, Healey JS, Ezekowitz M, Commerford P, Avezum A, Pais $\mathrm{P}$, et al. Variations in cause and management of atrial fibrillation in a prospective registry of 15,400 emergency department patients in 46 countries: the RE-LY Atrial Fibrillation Registry. Circulation 2014;129(15):1568-1576. doi:10.1161/CIRCULATIONAHA.113.005451. 